\title{
Tantalum Nitride Films Grown by Inorganic Low Temperature Thermal Chemical Vapor Deposition Diffusion Barrier Properties in Copper Metallization
}

\author{
Alain E. Kaloyeros,,${ }^{\mathrm{a}, *}$ Xiaomeng Chen, ${ }^{\mathrm{a}}$ Tanja Stark, ${ }^{\mathrm{a}}$ Kaushik Kumar, ${ }^{\mathrm{a}}$ Soon-Cheon Seo, ${ }^{\mathrm{a}}$ \\ Gregory G. Peterson, ${ }^{\mathrm{a}}$ Harry L. Frisch, ${ }^{\mathrm{a}}$ Barry Arkles, ${ }^{\mathrm{b}}$ and John Sullivan ${ }^{\mathrm{c}}, *$ \\ ${ }^{a}$ New York State Center for Advanced Thin Film Technology and Department of Physics, The University at Albany-SUNY, Albany, \\ New York 12222, USA \\ ${ }^{b}$ Gelest Incorporated, Tullytown, Pennsylvania 19007, USA \\ ${ }^{c}$ MKS Instrument Incorporated, Andover, Massachusetts 01810, USA
}

\begin{abstract}
Key findings are presented from a systematic study which evaluated the performance of chemical vapor deposited (CVD) nitrogenrich tantalum nitride $\left(\mathrm{TaN}_{x}, x \sim 1.8\right)$ films as a diffusion barrier in copper $(\mathrm{Cu})$ based metallization schemes. For this purpose, $3800 \AA$ thick Cu films were grown by physical vapor deposition (PVD) on $550 \AA$ A thick $\operatorname{TaN}_{x}$ films which were deposited by low temperature $\left(<425^{\circ} \mathrm{C}\right)$ thermal CVD (TCVD) using tantalum pentabromide $\left(\mathrm{TaBr}_{5}\right)$, ammonia, and hydrogen as coreactants. The resulting stacks

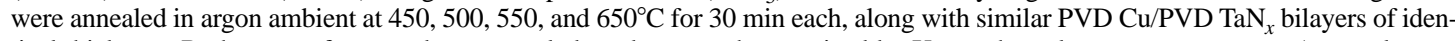
tical thickness. Both types of pre- and postannealed stacks were characterized by X-ray photoelectron spectroscopy, Auger electron spectroscopy, Rutherford backscattering spectrometry, nuclear reaction analysis for hydrogen profiling, X-ray diffraction, stack sheet resistance measurements, and Secco chemical treatment and etch-pit observation by scanning electron microscopy. The resulting findings showed that the PVD TaN $x$ films provided an excellent barrier against $\mathrm{Cu}$ diffusion throughout the annealing window investigated. Alternatively, the $\mathrm{TCVD} \mathrm{TaN}_{x}$ films exhibited similar stability up to $550^{\circ} \mathrm{C}$. Barrier failure occurred, however, at temperatures between 550 and $600^{\circ} \mathrm{C}$, as revealed by the formation of etch pits after Secco etch treatment. The failure of the TCVD TaN films

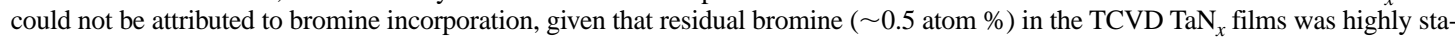
ble against thermal diffusion in the temperature window investigated. Instead, the higher thermal stability of the PVD TaN ${ }_{x}$ was attributed to differences in film microstructure and crystalline phase, or the location of excess nitrogen within the film matrix.
\end{abstract}

(C) 1999 The Electrochemical Society. S0013-4651(98)04-001-4. All rights reserved.

Manuscript submitted April 3, 1998; revised manuscript received August 12, 1998.

As the microelectronics industry evolves into ultralarge scale integration (ULSI) device schemes, copper $(\mathrm{Cu})$ appears to provide better performance as an interconnect material than the currently used aluminum (Al) alloys. In this respect, $\mathrm{Cu}$ offers lower resistivity and enhanced electromigration resistance than its $\mathrm{Al}$ counterpart. ${ }^{1}$ Unfortunately, $\mathrm{Cu}$ is known to be highly reactive with and a fast diffuser in silicon. Its presence in silicon leads to the formation of deep trap levels, which severely degrade device performance. ${ }^{2}$ Clearly, a critical issue in the realization of structurally stable copper-based metallization architectures is the development of an appropriate diffusion barrier which prevents undesirable interactions between $\mathrm{Cu}$ and the semiconductor and dielectric regions of the computer chip.

In order to address this issue, various refractory metals and their binary nitrides, as well as ternary metal-silicon-nitrogen compounds, have been heavily examined. Of these materials, tantalum (Ta)-based compounds are considered perhaps among the most promising candidates. Tantalum and its nitrides are highly refractory materials that are stable to extremely high temperatures. ${ }^{3}$ Additionally, they are known to be thermodynamically stable with respect to $\mathrm{Cu}$, as documented by the absence of $\mathrm{Cu}-\mathrm{Ta}$ or $\mathrm{Cu}-\mathrm{N}$ compounds. This stability is supported by a large number of studies pertaining to the appropriateness of Ta compounds as copper diffusion barrier. For instance, a sputtered $50 \mathrm{~nm}$ thick Ta barrier has demonstrated its resistance to $\mathrm{Cu}$ diffusion up to $550^{\circ} \mathrm{C}$ for $1 \mathrm{~h} .{ }^{4}$ In this respect, tantalum nitrides could provide even higher resistance to diffusion as compared to the pure metal, because of their dense interstitial crystalline structure. ${ }^{5}$ As a result, sputtered tantalum nitrides have been successfully shown to act as good diffusion barriers in $\mathrm{Cu}$ technology, with proven $\mathrm{Cu}-\mathrm{TaN}$ contact stability to temperatures as high as $750^{\circ} \mathrm{C} .^{2}$

Conventional forms of physical vapor deposition (PVD) of $\mathrm{TaN}_{x}$, including collimated sputtering, are inherently incapable of conformal step coverage in aggressive trench and via structures, given their "line of sight" type approach. Alternative processing techniques are thus

* Electrochemical Society Active Member. required for producing Ta-based liners for incorporation in subquartermicron device technologies. In this respect, chemical vapor deposition (CVD) is one of the most promising techniques. CVD exhibits an intrinsic potential for conformal coverage, in view of the "catalytic" role that the substrate plays in the deposition reaction.

Numerous CVD approaches have already been investigated for the growth of tantalum nitride. Inorganic CVD from tantalum pentachloride $\left(\mathrm{TaCl}_{5}\right)$ led to the deposition of tantalum nitride at temperatures above $600^{\circ} \mathrm{C} .{ }^{6}$ Clearly, this high processing temperature prohibits the use of this deposition methodology in actual semiconductor devices. Metallorganic CVD (MOCVD) approaches, on the other hand, included the use of various precursors such as the dialkylamido Ta complex, ${ }^{7} \mathrm{Ta}(\mathrm{NEt})\left(\mathrm{NEt}_{2}\right)_{3} / \mathrm{Ta}\left(\eta^{2} \mathrm{EtN}=\mathrm{CMeH}\right)\left(\mathrm{NEt}_{2}\right)_{3}$ blend, ${ }^{8}$ and $\mathrm{Ta}=\mathrm{NBu}^{\mathrm{t}}\left(\mathrm{NEt}_{2}\right)_{3},{ }^{9}$ etc. Unfortunately, various issues, including high deposition temperature $\left(>500^{\circ} \mathrm{C}\right)$, the incorporation of up to 40 atom $\%$ hydrogen, and the inclusion of several atomic percent of $\mathrm{C}$ and $\mathrm{O}$ seriously limited their technological usefulness.

In view of these issues, work by the present investigators has focused on the development of a low temperature thermal CVD (TCVD) process which employs simple inorganic Ta compounds. The latter are selected with primary bonds that are relatively weak. Such bonds are thus easily cleaved at low temperature, and their recombination can be interrupted by the presence of nitrogen to yield tantalum nitride. A candidate compound of this type is tantalum pentabromide $\left(\mathrm{TaBr}_{5}\right)$. The heat of formation for $\mathrm{TaBr}_{5}$ is $-143 \mathrm{kcal} / \mathrm{mol}$, as compared to $-205 \mathrm{kcal} / \mathrm{mol}$ for $\mathrm{TaCl}_{5},{ }^{10}$ implying that $\mathrm{TaBr}_{5}$ could potentially decompose at appreciably lower temperature than $\mathrm{TaCl}_{5}$.

This paper is the second in a series of reports on the identification and optimization of a low temperature inorganic TCVD route to $\mathrm{TaN}_{x}$ using $\mathrm{TaBr}_{5}$, ammonia $\left(\mathrm{NH}_{3}\right)$, and $\left(\mathrm{H}_{2}\right)$ as coreactants. ${ }^{11}$ The first report focused on the development of a low temperature TCVD process for the deposition of amorphous $\mathrm{TaN}_{x}$ films with $\mathrm{C}$, $\mathrm{O}$, and Br contamination levels below 1 atom $\%$, and better than $95 \%$ step coverage in nominally $0.3 \mu \mathrm{m}, 4.5: 1$ aspect ratio structures. ${ }^{11}$ In this article, key experimental details and associated findings are presented from a study which employed conventional PVD-grown $\mathrm{TaN}_{x}$ as 
Table I. Summary of process parameters for $\mathrm{TCVD} \mathrm{TaN}_{x}, \mathrm{PVD} \mathrm{TaN}_{x}$, and PVD Cu films.

\begin{tabular}{|c|c|c|c|c|c|}
\hline \multicolumn{2}{|c|}{$\operatorname{TCVD~TaN}_{x}$} & \multicolumn{2}{|c|}{$\operatorname{PVD~TaN}_{x}$} & \multicolumn{2}{|c|}{ PVD Cu } \\
\hline Parameter & Value & Parameter & Value & Parameter & Value \\
\hline Carrier gas & $\mathrm{H}_{2}(60 \mathrm{sccm})$ & Sputtering gas & $\operatorname{Ar}(50 \mathrm{sccm})$ & Sputtering gas & $\operatorname{Ar}(40 \mathrm{sccm})$ \\
\hline Reactant gas & $\mathrm{NH}_{3}(350 \mathrm{sccm})$ & Reactant gas & $\mathrm{N}_{2}(55 \mathrm{sccm})$ & Reactant gas & none \\
\hline Deposition pressure & 0.4 Torr & Deposition pressure & 5 mTorr & Deposition pressure & 4 mTorr \\
\hline Base pressure & $10^{-6}$ Torr & Base pressure & $10^{-8}$ Torr & Base pressure & $\sim 10^{-8}$ Torr \\
\hline Substrate temperature & $425^{\circ} \mathrm{C}$ & Substrate temperature & $25^{\circ} \mathrm{C}$ & Substrate Temperature & $25^{\circ} \mathrm{C}$ \\
\hline Source temperature & $160^{\circ} \mathrm{C}$ & Plasma power $(\mathrm{dc})$ & $2 \mathrm{~kW}$ & Plasma power $(\mathrm{dc})$ & $2 \mathrm{~kW}$ \\
\hline
\end{tabular}

baseline, and which aimed to establish a thorough assessment of the performance of the TCVD-grown $\mathrm{TaN}_{x}$ from $\mathrm{TaBr}_{5}$ as diffusion barrier in $\mathrm{Cu}$ metallization.

\section{Experimental}

Description of processing conditions. - In a first step, $550 \AA$ thick TCVD and PVD $\mathrm{TaN}_{x}$ films were deposited on $\mathrm{Si}(100)$ substrates. Prior to deposition, the $\mathrm{Si}$ substrates received a standard organic clean process consisting of a 1 min bath in trichloroethylene, acetone, and then methanol, followed by $10 \% \mathrm{HF}$ clean to remove native oxide. All samples were subsequently in situ plasma cleaned in their respective CVD and PVD processing modules prior to actual deposition. In the case of TCVD $\mathrm{TaN}_{x}$ films, processing was performed in a custom-designed, warm wall, plasma capable, stainless steel CVD reactor. Relevant details of the deposition process have been described elsewhere and are not reported herein. ${ }^{12}$

In the case of PVD $\mathrm{TaN}_{x}$, conventional sputter deposition was carried out in a commercial Varian $\mathrm{MB}^{2}$ cluster tool system using an electronic grade Ta target. The target was in a nitrided mode during actual deposition. Table I summarizes the key process parameters for the deposition of TCVD and PVD $\mathrm{TaN}_{x}$ films.

In a second step, the PVD and TCVD TaN ${ }_{x}$ films were exposed to 30 min anneals each in an argon ambient at temperatures of 450, 500, 550,600 , and $650^{\circ} \mathrm{C}$. The goal was to explore and document any thermally induced compositional or structural changes in the $\mathrm{TaN}_{x}$ films that might influence the subsequent $\mathrm{Cu} / \mathrm{TaN}_{x}$ stack annealing studies.

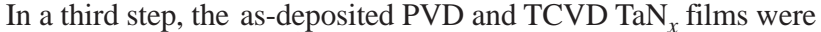
processed to deposit $3800 \AA$ thick $\mathrm{Cu}$ films by noncollimated sputtering to form $\mathrm{Cu} / \mathrm{TaN}_{x} / \mathrm{Si}$ contact systems. $\mathrm{Cu}$ deposition was carried out in a commercial CVC connection cluster tool, using the process parameters listed in Table I. The resulting $\mathrm{Cu} / \mathrm{TaN}_{x}$ stacks were subsequently annealed in Ar ambient for 30 min each at five settings: $450,500,550,600$, and $650^{\circ} \mathrm{C}$.

Description of characterization techniques.-A thorough evaluation of the microchemical, microstructural, and barrier properties properties of all $\mathrm{TaN}_{x}$ films was carried out at the analytical facilities of the New York State Center for Advanced Thin Film Technology. The analytical techniques used included Auger electron spectroscopy (AES), X-ray photoelectron spectroscopy (XPS), Ruther- ford backscattering spectrometry (RBS), X-ray diffraction (XRD), four-point resistivity probe, nuclear reaction analysis (NRA) for hydrogen profiling, and scanning electron microscopy (SEM). Key details of the analytical methods applied have already been discussed elsewhere. ${ }^{12}$

Additionally, etch pit observation was performed by selectively removing the $\mathrm{Cu}$ and $\mathrm{TaN}_{x}$ layers, in a first stage, using a wet chemical etch solution consisting of a 1:1 ratio of nitric acid $\left(\mathrm{HNO}_{3}\right)$ and distilled water $\left[\mathrm{H}_{2} \mathrm{O}\right.$ for $\mathrm{Cu}$ and $49 \%$ hydrofluoric acid (HF) in distilled $\mathrm{H}_{2} \mathrm{O}$ for $\mathrm{TaN}_{x}$ ]. The $\mathrm{Si}$ substrates were then exposed for $5 \mathrm{~s}$ to a Secco etch solution which consisted of one part by volume of $0.15 \mathrm{M}$ potassium dichromate $\left(\mathrm{K}_{2} \mathrm{Cr}_{2} \mathrm{O}_{7}\right)$ in $\mathrm{H}_{2} \mathrm{O}$ and two parts $\mathrm{HF} .{ }^{13}$

\section{Results and Discussion}

Characterization of pre- and postannealed $T_{a} N_{x}$ films prior to $\mathrm{Cu}$ processing. - Table II summarizes the properties of as-deposited TCVD and PVD TaN ${ }_{x}$ films. Prior to $\mathrm{Cu}$ deposition and annealing experiments, both types of $\mathrm{TaN}_{x}$ films were exposed to the same annealing recipes used for the $\mathrm{Cu} / \mathrm{TaN}_{x} / \mathrm{Si}$ contact systems, namely, 450 to $650^{\circ} \mathrm{C}$ in $50^{\circ} \mathrm{C}$ steps. The purpose was to establish baseline performance metrics, and determine the effects of thermal treatment on key $\mathrm{TaN}_{x}$ films characteristics, including $\mathrm{Br}$ concentration and film microstructure.

For illustration purposes, Fig. 1 displays the RBS spectra of TCVD $\mathrm{TaN}_{x}$ as-deposited and after annealing at $650^{\circ} \mathrm{C}$. There was no change observed in $\mathrm{Br}$ concentration and peak profile before and after all annealing steps. This finding supports the expectation that small bromine concentration might require appreciably high thermal energy to diffuse out of the $\mathrm{TaN}_{x}$ lattice, and are thus expected to have no negative effect on $\mathrm{Cu} / \mathrm{TaN}_{x} / \mathrm{Si}$ material reliability.

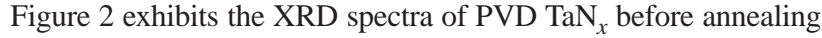
(a) and after annealing at $450^{\circ} \mathrm{C}$ (b) and at $650^{\circ} \mathrm{C}$ (c). The XRD spectrum of the as-deposited film consisted primarily of broad reflection peaks that correspond to a nanocrystalline cubic TaN phase, possibly within an amorphous matrix. The XRD reflection peaks became increasingly sharper and more intense with higher annealing temperature. In particular, the full-width-at-half-maximum (fwhm) for the $\mathrm{TaN}$ (111) peak decreased continuously from $2.42^{\circ}$ for the as-deposited film to $1.81^{\circ}$ for the film annealed at $650^{\circ} \mathrm{C}$. This was accompanied

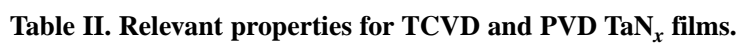

Property (analytical technique)

Thickness (RBS)

Stoichiometry (AES)

Density $\left(\mathrm{g} / \mathrm{cm}^{3}\right)(\mathrm{SEM}+\mathrm{RBS}+$ AES $)$

Light element impurities (AES and XPS)

Hydrogen incorporation (hydrogen profiling)

Heavy element incorporation (XPS, RBS)

Structure (XRD)

Resistivity (four-point probe)

Phase (XPS)
TCVD $\operatorname{TaN}_{x}$

$\operatorname{PVD~TaN}_{x}$
$550 \AA$

$\mathrm{TaN}_{1.83 \pm 0.12}$

9.70

$\mathrm{C}$ below detection limits $\mathrm{O}<2.5$ atom \% $<1$ atom \%

$\leq 0.5$ atom $\% \mathrm{Br}$, Ar below detection limits amorphous

$$
\sim 2500 \mu \Omega \mathrm{cm}
$$

Mixture of phases
$550 \AA$

$\mathrm{TaN}_{1.71 \pm 0.09}$

10.17

$\mathrm{O}$ and $\mathrm{C}$ below detection limits $\sim 1$ atom $\%$

$\sim 1$ atom \% Ar, Br below detection limits Nanocrystalline cubic TaN phase within an amorphous matrix $\sim 3100 \mu \Omega \mathrm{cm}$

Mixture of phases 

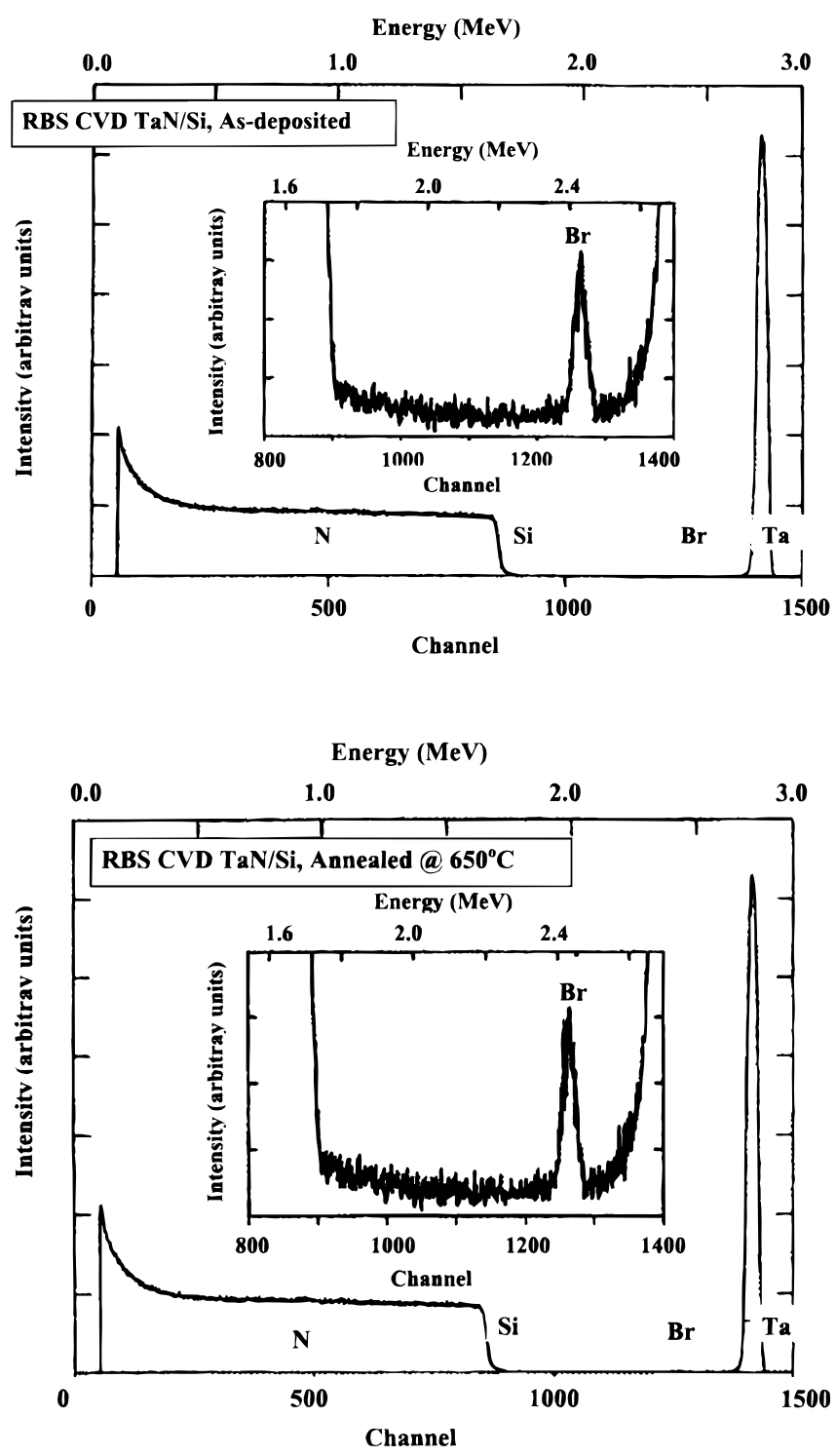

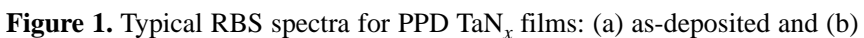
annealed at $650^{\circ} \mathrm{C}$. The $\mathrm{Br}$ RBS peak is shown magnified in the insets.

by the detection of very weak and broad peaks that correspond to a $\mathrm{Ta}_{3} \mathrm{~N}_{5}$ phase.

Similarly, Fig. 3 displays the XRD spectra for TCVD $\mathrm{TaN}_{x}$ before (a) and after annealing at 450 (b), 650 (c), and $700^{\circ} \mathrm{C}$ (d). There were no observed changes between the XRD profiles of the as-deposited samples and the samples annealed up to $600^{\circ} \mathrm{C}$, with all samples exhibiting the characteristic XRD spectrum of a mainly amorphous phase. Crystallization of the films was detected between 600 and $650^{\circ} \mathrm{C}$ annealing temperature. Further annealing at $700^{\circ} \mathrm{C}$ for $30 \mathrm{~min}$ in Ar ambient led to the identification of a dominant $\mathrm{Ta}_{3} \mathrm{~N}_{5}$ structure in coexistence with hexagonal TaN.

Diffusion barrier performance of PVD TaN $N_{x}$-Figure 4 presents the RBS spectrum of postannealed $\left(650^{\circ} \mathrm{C}\right) \mathrm{Cu} / \mathrm{PVD} \mathrm{TaN}_{x} / \mathrm{Si}$ stacks after $\mathrm{Cu}$ strip, with the $\mathrm{Ar}$ and $\mathrm{Cu}$ peaks shown magnified in the inset. No changes were observed in the RBS spectra of the as-deposited PVD TaN ${ }_{x}$ films and those exposed to $\mathrm{Cu}$ deposition and annealing up to $650^{\circ} \mathrm{C}$. This finding is supported by the RBS studies of Holloway et al. ${ }^{5}$ which showed Ta outdiffusion to the $\mathrm{Cu}$ surface for the $\mathrm{Cu} / \mathrm{Ta} / \mathrm{Si}$ material system after thermal treatment at $550^{\circ} \mathrm{C}$. This motion was followed by the migration of $\mathrm{Cu}$ through the Ta barrier to the $\mathrm{Si}$ interface and the formation of a $\mathrm{Cu}_{3} \mathrm{Si}$ phase. This phenome-

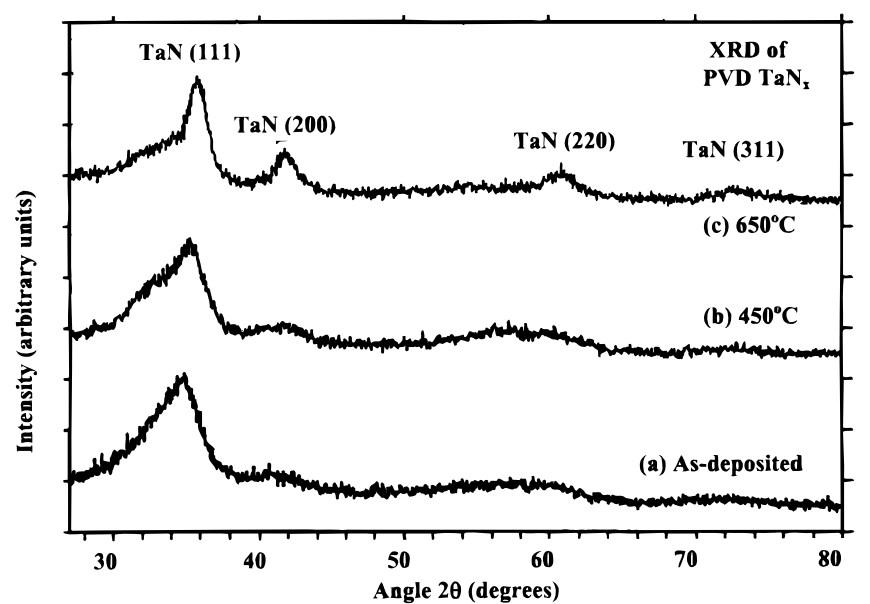

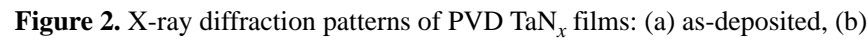
annealed at $450^{\circ} \mathrm{C}$, and (c) annealed at $650^{\circ} \mathrm{C}$.

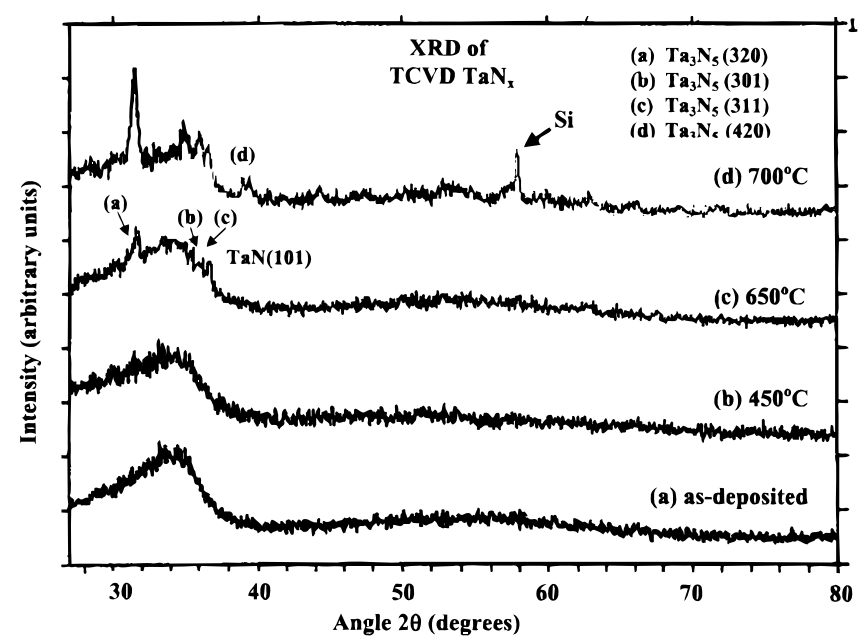

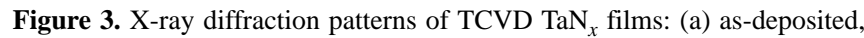
(b) annealed at $450^{\circ} \mathrm{C}$, (c) annealed at $650^{\circ} \mathrm{C}$, and (d) annealed at $700^{\circ} \mathrm{C}$.

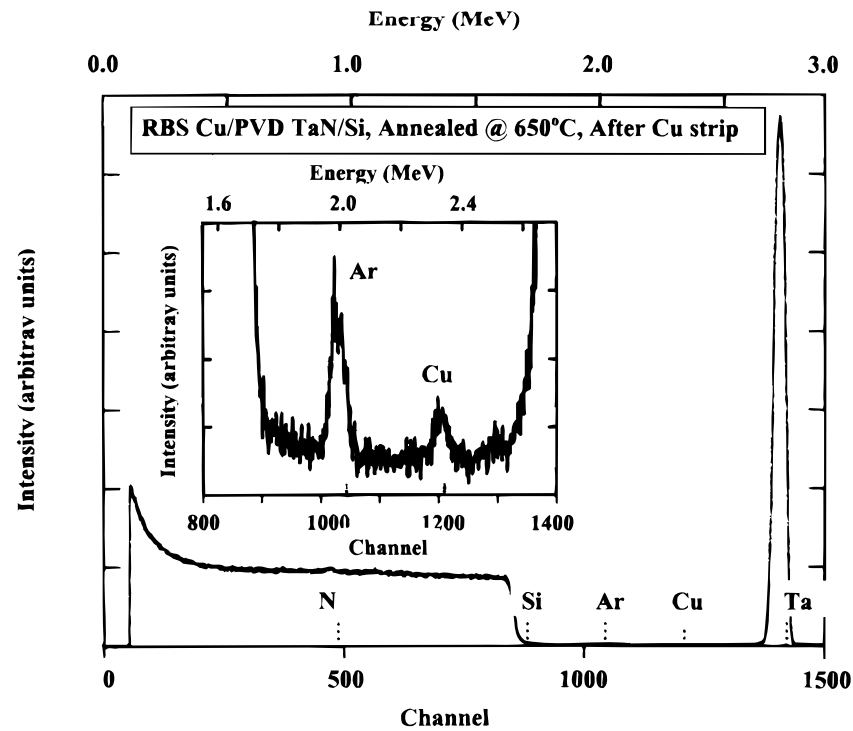

Figure 4. RBS spectra of a Cu/PVD TaN $/$ /Si stack after annealing at $650^{\circ} \mathrm{C}$, and subsequent $\mathrm{Cu}$ strip. The $\mathrm{Ar}$ and $\mathrm{Cu}$ peaks are shown magnified in the inset. 


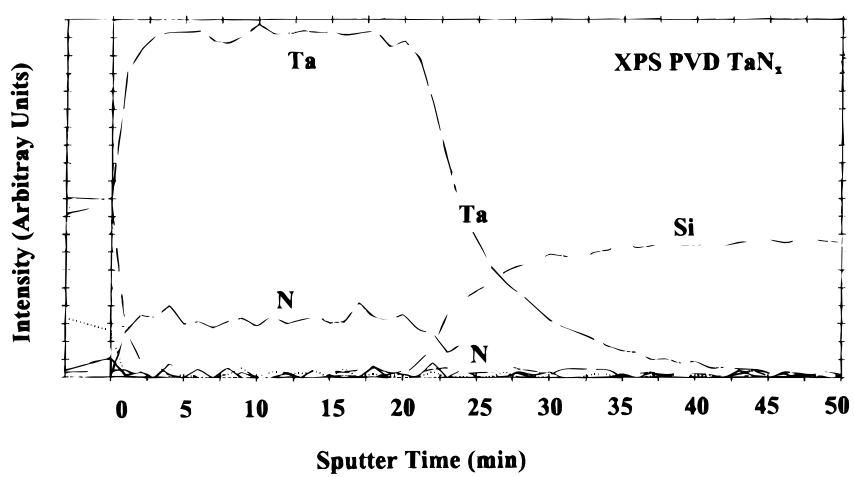

Figure 5. XPS depth profile of a Cu/PVD $\mathrm{TaN}_{x} / \mathrm{Si}$ stack after annealing at $650^{\circ} \mathrm{C}$ and subsequent $\mathrm{Cu}$ strip.

non was suppressed in the case of the $\mathrm{Cu} / \mathrm{Ta}_{2} \mathrm{~N} / \mathrm{Si}$ system, where $\mathrm{Ta}_{2} \mathrm{~N}$ exhibited thermal stability up to $650^{\circ} \mathrm{C}$.

Our RBS results were supported by the XPS results shown in Fig. 5, which displays XPS depth profile for postannealed $\left(650^{\circ} \mathrm{C}\right)$ $\mathrm{Cu} / \mathrm{PVD} \mathrm{TaN}_{x} / \mathrm{Si}$ after $\mathrm{Cu}$ strip. No $\mathrm{Cu}$ or Ta diffusion was observed within the detection limits of XPS. Similarly, XRD investigations of $\mathrm{Cu} / \mathrm{PVD} \mathrm{TaN}_{x} / \mathrm{Si}$ stacks confirmed the RBS and XPS data, as shown in the XRD spectra of Fig. $6 \mathrm{a}$ and $\mathrm{b}$ for $\mathrm{Cu} / \mathrm{PVD} \mathrm{TaN} / \mathrm{Si}$ stacks before (a) and after annealing at $650^{\circ} \mathrm{C}$ (b). Strong $\mathrm{Cu}(111), \mathrm{Cu}(200)$, and $\mathrm{Cu}(220)$ reflection lines are seen, along with weak and broad $\mathrm{TaN}_{x}$ peaks. XRD did not detect the presence of any phase formation and confirmed the high thermal stability of $\mathrm{Cu} / \mathrm{PVD} \mathrm{TaN}_{x} / \mathrm{Si}$ stacks. No etch pits were observed by SEM after Secco etch treatment of the $\mathrm{Cu} / \mathrm{PVD} \mathrm{TaN}_{x} / \mathrm{Si}$ system, even for the samples annealed at $650^{\circ} \mathrm{C}$.

Diffusion barrier performance of TCVD TaN $\mathrm{T}_{x}$ - The work discussed above was repeated for $\mathrm{Cu} / \mathrm{TCVD} \mathrm{TaN}_{x} / \mathrm{Si}$ stacks. In this respect, XPS did not indicate any $\mathrm{Cu}$ or Ta interdiffusion even after the $650^{\circ} \mathrm{C}$ thermal treatment step, as shown in Fig. 7 which displays the XPS depth profile for postannealed $\left(650^{\circ} \mathrm{C}\right) \mathrm{Cu} / \mathrm{TCVD} \mathrm{TaN}_{x} / \mathrm{Si}$ after $\mathrm{Cu}$ strip. No $\mathrm{Cu}$ was detected in the $\mathrm{TaN}_{x}$ or $\mathrm{Si}$ within the detection limits of XPS $(\sim 1$ atom $\%)$. XRD yielded the same results as in the case of PVD TaN ${ }_{x}$. As illustration, Fig. 8 presents the XRD spectra of as-deposited (a) and after $650^{\circ} \mathrm{C}$ annealed (b) $\mathrm{Cu} / \mathrm{TCVD} \mathrm{TaN}_{x} / \mathrm{Si}$ stacks after $\mathrm{Cu}$ strip. No material interaction or phase formation were seen in the XRD spectra, even after the $650^{\circ} \mathrm{C}$ anneal. The strong reflection peaks in Fig. 8 corresponded to $\mathrm{Cu}$ (111), $\mathrm{Cu}$ (200), and $\mathrm{Cu}$ (220), while the broad and weak peaks were due to TCVD TaN $x$.

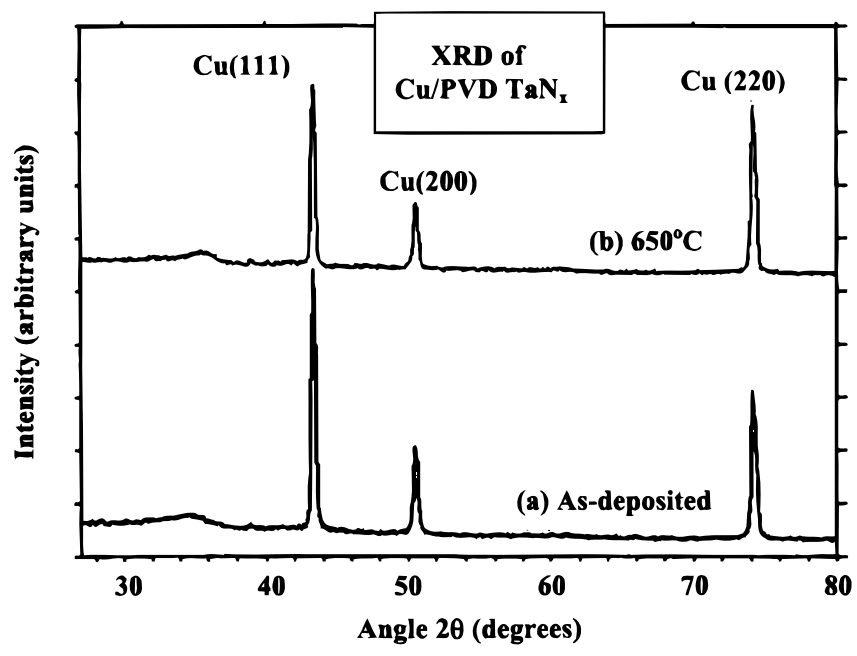

Figure 6. XRD spectra of a Cu/PVD $\mathrm{TaN}_{x} / \mathrm{Si}$ stack: (a) as-deposited and (b) annealed at $650^{\circ} \mathrm{C}$.

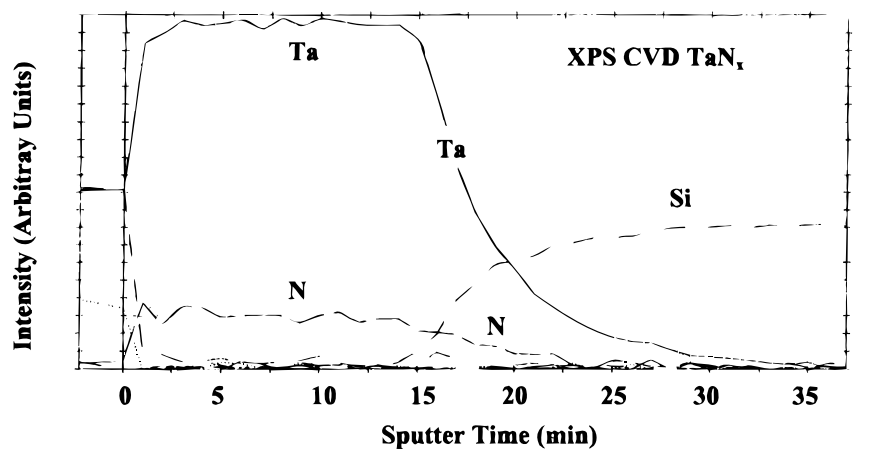

Figure 7. XPS depth profile of a $\mathrm{Cu} / \mathrm{TCVD} \mathrm{TaN}_{x} / \mathrm{Si}$ stack after annealing at $650^{\circ} \mathrm{C}$ and subsequent $\mathrm{Cu}$ strip.

RBS analysis yielded, on the other hand, different results as documented in Fig. 9a-d. These figures display the magnified $\mathrm{Ar}, \mathrm{Cu}$, and $\mathrm{Br}$ RBS peaks in TCVD $\mathrm{TaN}_{x}$ after $\mathrm{Cu}$ strip for, respectively, asdeposited and annealed $\left(550,600\right.$, and $\left.650^{\circ} \mathrm{C}\right) \mathrm{Cu} / \mathrm{TCVD} \mathrm{TaN}_{x} / \mathrm{Si}$ stacks. No change was observed in the spectra up to $550^{\circ} \mathrm{C}$ thermal treatment. However, at higher annealing temperatures, the $\mathrm{Cu}$ peak increased in width and intensity, indicating the motion of small amounts of $\mathrm{Cu}$ into the $\mathrm{TaN}_{x}$ films. In this respect, Fig. 10 plots the RBS integrated $\mathrm{Cu}$ peak intensities in both PVD and TCVD films as a function of annealing temperature. A marked increase in the num-

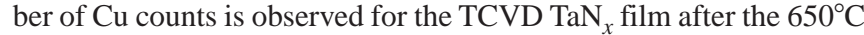
annealing step.

Secco etching of the $\mathrm{Cu} / \mathrm{TCVD} \mathrm{TaN} \mathrm{T}_{x} / \mathrm{Si}$ contact systems did not reveal any etch pits in $\mathrm{Si}$ for samples heat-treated up to $550^{\circ} \mathrm{C}$, as shown in the SEM micrograph of Fig. 11. Alternatively, SEM micrographs of similar samples revealed the presence of rectangularly shaped etch pits in $\mathrm{Si}$, with the size of a few microns after treatment at higher temperature. This is illustrated in Fig. 12 and 13 for the samples treated at, respectively, 600 and $650^{\circ} \mathrm{C}$.

\section{Discussion}

The results reported above indicate that the PVD and TCVD TaN films exhibited different diffusion barrier performance in $\mathrm{Cu}$ metallization, with the TCVD $\mathrm{TaN}_{x}$ film beginning to fail above $550^{\circ} \mathrm{C}$, while its PVD counterpart shows thermal integrity up to $650^{\circ} \mathrm{C}$. This

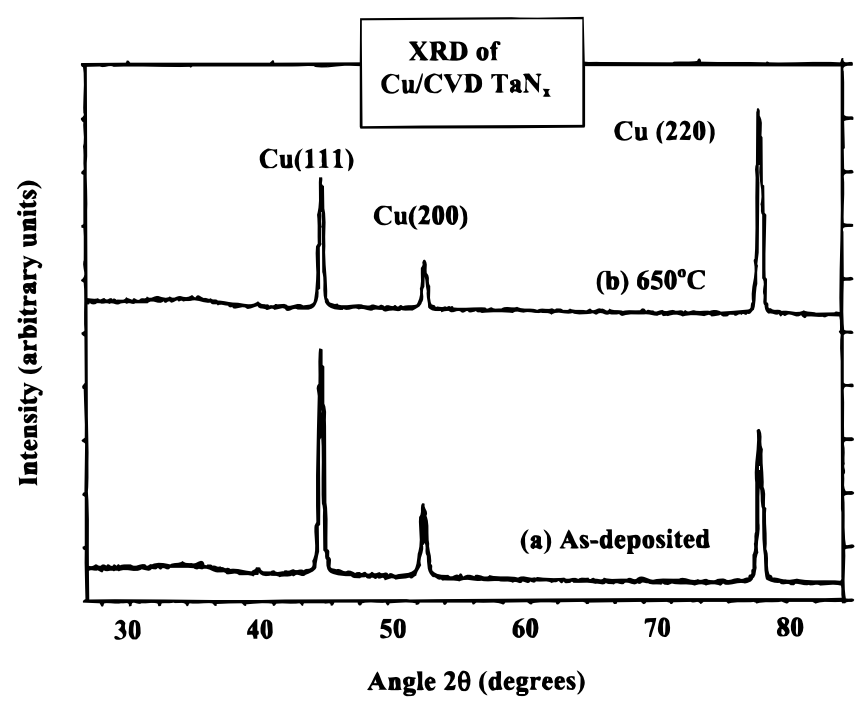

Figure 8. XRD spectra of a $\mathrm{Cu} / \mathrm{TCVD} \mathrm{TaN} / \mathrm{Si}$ stack: (a) as-deposited and (b) annealed at $650^{\circ} \mathrm{C}$. 
difference in behavior could not be attributed to the presence of bromine in the TCVD TaN ${ }_{x}$, given that no variations in $\mathrm{Br}$ concentration or peak profile were observed even after thermal treatment at $650^{\circ} \mathrm{C}$. The high thermal stability of $\mathrm{Br}$ was seen for annealed TCVD $\mathrm{TaN}_{x}$ both before $\mathrm{Cu}$ deposition, as documented in the RBS spectra of Fig. 1, and after $\mathrm{Cu}$ deposition, followed by $\mathrm{Cu} / \mathrm{TCVD} \mathrm{TaN}_{x} / \mathrm{Si}$ stack anneal, and $\mathrm{Cu}$ strip. The same expectation applies to other impurities in the $\mathrm{TaN}_{x}$ films, given that their concentrations were too small to significantly influence barrier properties.

In terms of thermal stress behavior, two competing breakdown mechanisms were reported for different phases of tantalum nitride. In the case of stoichiometric $\mathrm{TaN}, \mathrm{Cu}$ was found to migrate into the $\mathrm{Si}$ substrate without reacting with the barrier layer. In comparison, $\mathrm{Ta}_{2} \mathrm{~N}$ failed due to an interfacial reaction between $\mathrm{Si}$ and the barrier layer, followed by $\mathrm{Cu}$ diffusion to the interface. The failure mechanism in this case was independent of whether the barrier was amorphous ${ }^{14}$ or crytalline. ${ }^{2}$ In our case, no reaction was observed between Si and either the PVD or TCVD TaN $x$ barrier, and no tantalum silicide was detected regardless of the thermal treatment applied. Furthermore, density variations between the two types of films were not significant enough to justify the marked difference in barrier performance.

The different thermal stress behaviors of the TCVD and PVD $\mathrm{TaN}_{x}$ films could be attributed to the observed differences in their microstructure, and resulting variations in crystallization behavior as seen in Fig. 2 and 3. In this respect, no abrupt change was seen in the microstructure of the PVD films with annealing temperature. Primarily, a nanocrystalline cubic TaN phase was detected in the as-deposited films, with a slow evolution in grain size growth occurring with higher temperatures. Conversely, the TCVD films exhibited an amorphous structure up to $600^{\circ} \mathrm{C}$, with crystallization into a predominantly $\mathrm{Ta}_{3} \mathrm{~N}_{5}$ phase in co-existence with a hexagonal TaN matrix occurring above that temperature. It is suggested that crystallization of the

\section{Energy (MeV)}
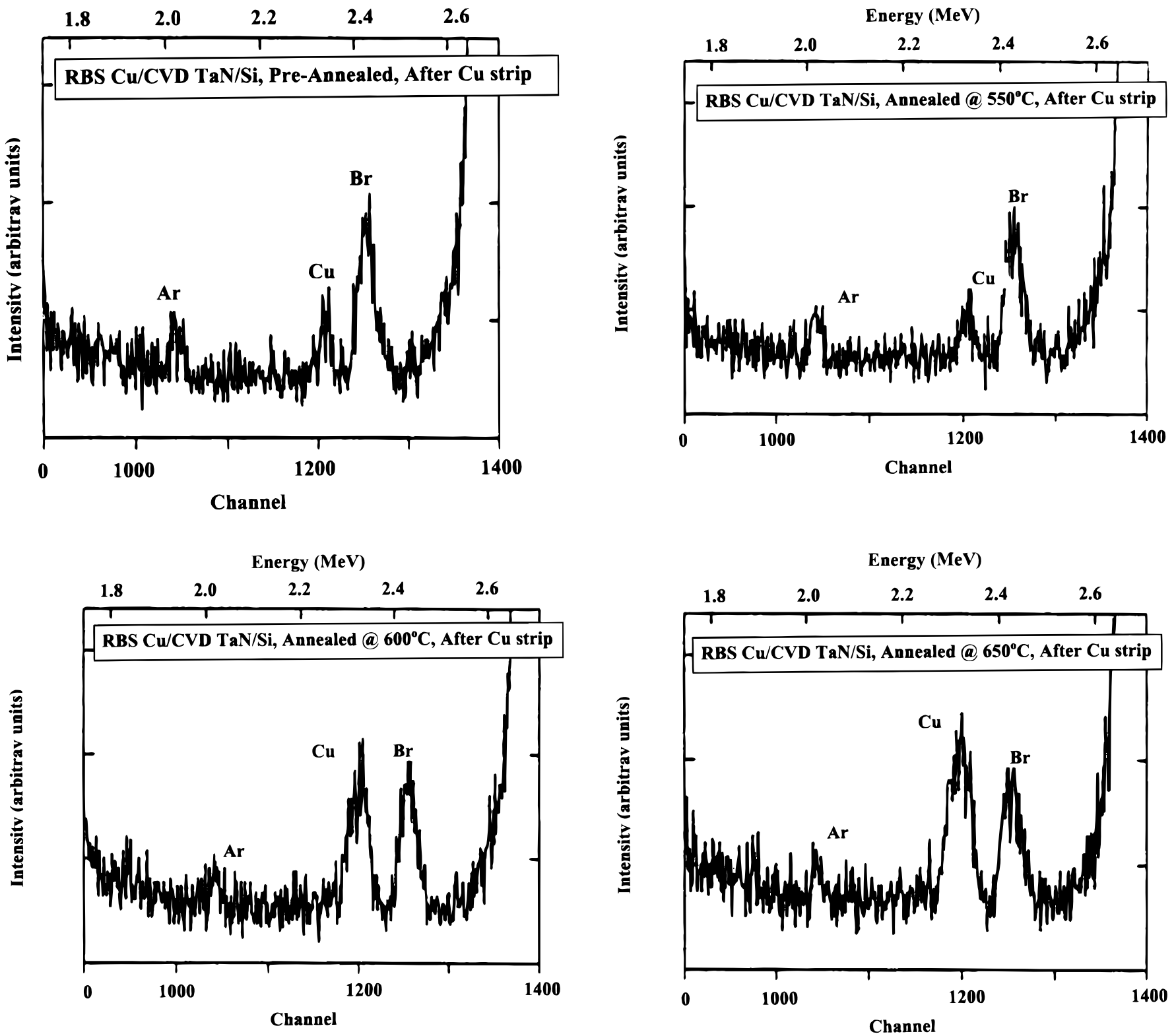

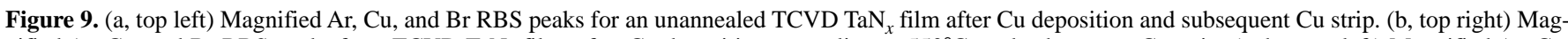
nified $\mathrm{Ar}, \mathrm{Cu}$, and $\mathrm{Br}$ RBS peaks for a TCVD TaN ${ }_{x}$ film, after $\mathrm{Cu}$ deposition, annealing at 550 ${ }^{\circ} \mathrm{C}$, and subsequent $\mathrm{Cu}$ strip. (c, bottom left) $\mathrm{Magnified} \mathrm{Ar}$, Cu,

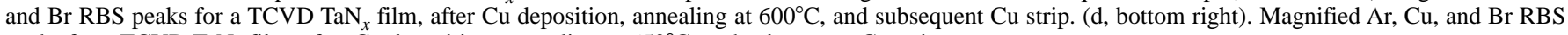
peaks for a TCVD $\mathrm{TaN}_{x}$ film, after $\mathrm{Cu}$ deposition, annealing at $650^{\circ} \mathrm{C}$, and subsequent $\mathrm{Cu}$ strip. 


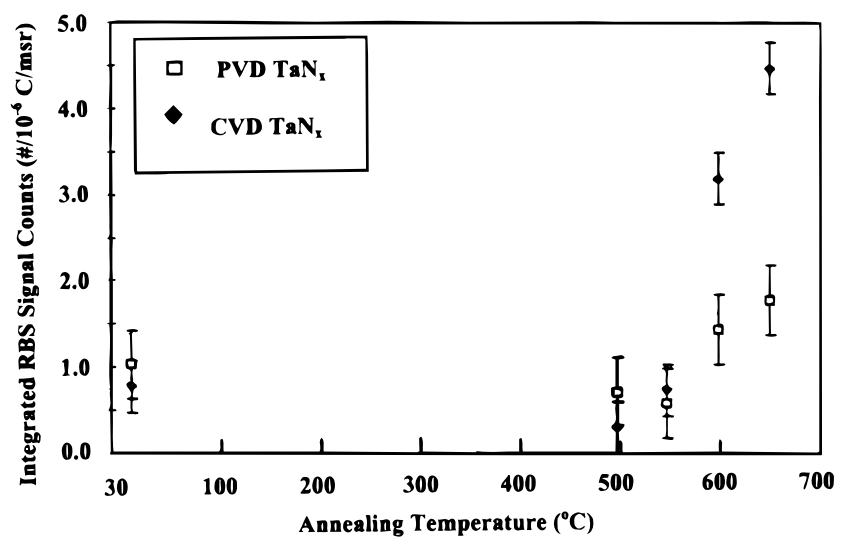

Figure 10. Integrated RBS Cu peak intensities in PVD and TCVD TaN ${ }_{x}$ as a function of annealing temperature. Data is shown for films after $\mathrm{Cu}$ deposition, $\mathrm{Cu} / \mathrm{TaN}_{x}$ stack anneal, and subsequent $\mathrm{Cu}$ strip.

amorphous TCVD films, and the associated formation of grain boundaries, might have provided a path for $\mathrm{Cu}$ diffusion.

Alternatively, even though both types of $\mathrm{TaN}_{x}$ films were highly $\mathrm{N}$ rich, the location of excess $\mathrm{N}$ within the film matrix might have been different. In the case of the TCVD films, the N:Ta ratio was close to $\mathrm{Ta}_{3} \mathrm{~N}_{5}$, and the films ultimately crystallized into a predominant $\mathrm{Ta}_{3} \mathrm{~N}_{5}$ phase. In contrast, the PVD films were mainly cubic $\mathrm{TaN}$, which clearly corresponds to a $1: 1$ ratio for $\mathrm{N}$ :Ta. This implies that the excess $\mathrm{N}$ in the PVD $\mathrm{TaN}_{x}$ might have been located interstitially, and at the grain boundaries of the $\mathrm{TaN}_{x}$ matrix. As such, it might have "stuffed" the grain boundaries and acted as a good barrier against diffusion along such pathways.

Nevertheless, both contact systems, namely, Cu/PVD $\mathrm{TaN}_{x} / \mathrm{Si}$ and $\mathrm{Cu} / \mathrm{TCVD} \mathrm{TaN}_{x} / \mathrm{Si}$ were stable up to $550^{\circ} \mathrm{C}$, a temperature well in excess of those experienced during the integrated circuitry fabrication flow.

\section{Conclusions}

A systematic evaluation was carried out of the barrier characteristics of nitrogen-rich $\mathrm{TaN}_{x}$ films grown by conventional PVD and

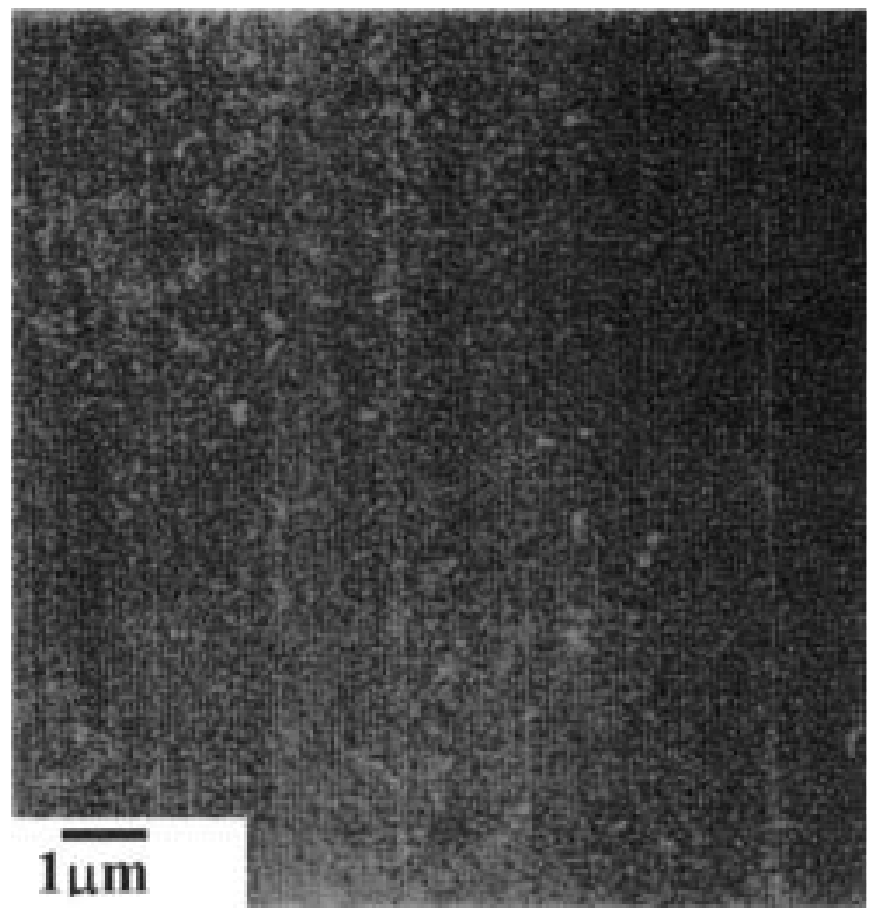

Figure 11. SEM micrographs of the $\mathrm{Si}$ surface after Secco etch for a $\mathrm{Cu} / \mathrm{TCVD} \mathrm{TaN}_{x} / \mathrm{Si}$ stack annealed at $550^{\circ} \mathrm{C}$.

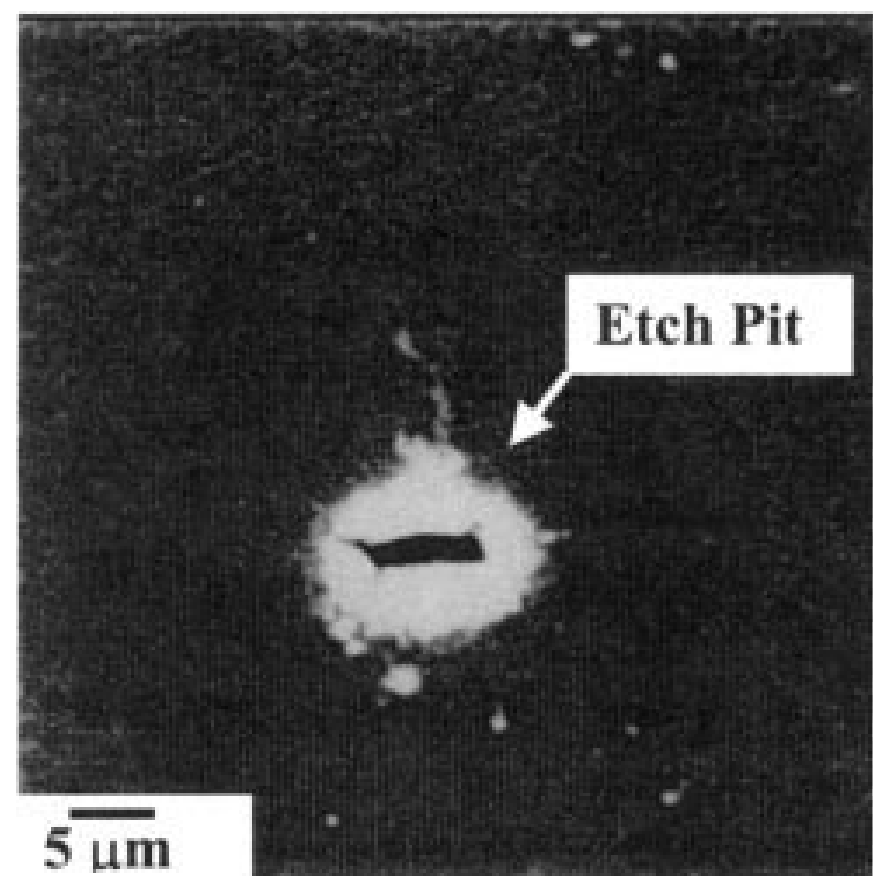

Figure 12. SEM micrographs of the $\mathrm{Si}$ surface after Secco etch for a $\mathrm{Cu} / \mathrm{TCVD} \mathrm{TaN}_{x} / \mathrm{Si}$ stack annealed at $600^{\circ} \mathrm{C}$.

low temperature inorganic CVD from $\mathrm{TaBr}_{5}$. The study demonstrated that the TCVD and PVD $\mathrm{TaN}_{x}$ films were stable against $\mathrm{Cu}$ diffusion up to temperatures of, respectively, 550 and $650^{\circ} \mathrm{C}$. The lower thermal performance of the TCVD films could not be attributed to the presence of bromine, given the high stability of $\mathrm{Br}$ against migration to temperatures in excess of $650^{\circ} \mathrm{C}$. Instead, it is suggested that variations in film microstructure or the location of excess $\mathrm{N}$ in the $\mathrm{TaN}_{x}$ matrix might have played a primary role in the observed difference in barrier performance.

\section{Acknowledgments}

The work was partially supported by the Semiconductor Research Corporation (SRC), Center for Advanced Interconnect Sci-

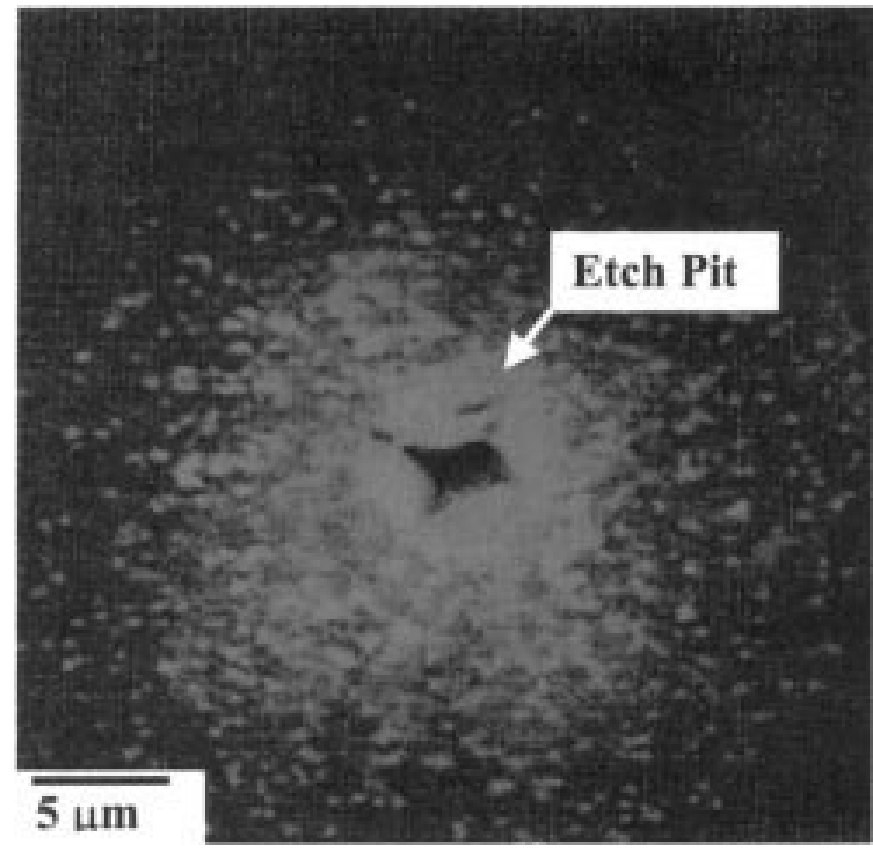

Figure 13. SEM micrographs of the Si surface after Secco etch for a $\mathrm{Cu} / \mathrm{TCVD} \mathrm{TaN}_{x} / \mathrm{Si}$ stack annealed at $650^{\circ} \mathrm{C}$. 
ence and Technology (CAIST), and the New York State Center for Advanced Thin Film Technology (CAT). This support is gratefully acknowledged.

University at Albany, State University of New York, assisted in meeting the publication costs of this article.

\section{References}

1. T. Nitta, T. Ohmi, S. Sakai, and T. Shibata, J. Electrochem. Soc., 140, 1131 (1993).

2. M. Takeyama, A. Noya, T. Sase, and A. Ohta, J. Vac. Sci. Technol., B, 14, 674 (1996).

3. CRC Handbook of Chemistry and Physics, 71th ed., D. Lide, Editor, pp. 4-109, CRC Press, Boston (1990-1991)
4. J. S. Reid, E. Kolawa, and M. Nicolet, J. Mater. Res., 7, 2424 (1992).

5. K. Holloway, P. M. Fryer, C. Cabral, and P. J. Bailey, J. Appl. Phys., 71, 5433 (1992).

6. K. Hieber, Thin Solid Film, 24, 157 (1974).

7. R. Fix, R. Gordon, and D. Hoffman, Chem. Mater, 5, 614 (1993).

8. H. Chiu and W. Chang, J. Mater. Sci. Lett., 11, 92 (1992).

9. M. Tsai, S. C. Sun, H. T. Chui, and S. H. Chuang, Appl. Phys. Lett., 67, 1129 (1995).

10. I. Barin, O. Knacke, and O. Kubaschewski, Thermochemical Properties of Inorganic Substances, Supplement, Springer-Verlag, Berlin (1977).

11. X. Chen, G. G. Peterson, C. Goldberg, G. Nuesca, H. L. Frisch, and A. E. Kaloyeros, J. Mater. Res., Submitted.

12. X. Chen, H. L. Frisch, and A. E. Karoyeros, J. Vac. Sci. Technol. B, Accepted (1998).

13. F. Secco d'Aragona, J. Electrochem. Soc., 119, 948 (1972).

14. K. H. Min, K. C. Chun, and K. B. Kim, J. Vac. Sci. Technol. B, 14, 3262 (1996). 